\title{
Numerical simulation of crustal deformation using a three-dimensional viscoelastic crustal structure model for the Japanese islands under east-west compression
}

\author{
Ikuo Cho and Yasuto Kuwahara \\ Geological Survey of Japan, National Institute of Advanced Industrial Science and Technology, Tsukuba Central 7, Tsukuba 305-8567, Japan
}

(Received February 26, 2013; Revised April 15, 2013; Accepted May 6, 2013; Online published October 9, 2013)

\begin{abstract}
The three-dimensional viscoelastic crustal structure beneath Japanese islands was modeled to simulate their crustal deformation by using a finite-element method and applying boundary conditions of the east-west horizontal compression. The result shows that there are relatively narrow zones of high strain rate at shallow depths, whose pattern is similar to that of the Niigata-Kobe tectonic zone revealed by GPS. High strain rates are not necessarily concentrated in regions where the elastic layer is relatively thin, but rather where its thickness changes abruptly.
\end{abstract}

Key words: Viscoelastic structure, rheology, modeling, numerical simulation, forecast, Niigata-Kobe tectonic zone, crustal deformation.

\section{Introduction}

A strong three-dimensional (3D) nonuniformity is likely to exist in the thermal structure of the crust and the upper mantle beneath Japanese islands, where cool oceanic plates are subducting while hot melts are rising from the mantle (Nakajima and Hasegawa, 2009) (Fig. 1). This nonuniformity is expected to affect the viscoelastic structure and ultimately cause deformation of the islands. For example, Shimamoto (1992) stated that the 3D viscoelastic structure of the crust affects the distribution of active faults. On the basis of two-dimensional (2D) simulations of the crustal deformation on time scales of $10^{5}$ to $10^{6}$ years, Shibazaki et al. $(2007,2008)$ indicated that faulting and crustal deformation are controlled by the nonuniformity of the thermal structure of the crust and the upper mantle beneath northeastern Japan.

We conducted numerical simulations of the crustal deformation of Japanese islands, with the ultimate goal of longterm (a few decades) forecasting of inland large earthquakes (Fig. 2). To this end, Cho and Kuwahara (2013) have modeled the thermal structure of the crust and the upper mantle beneath Japanese islands. In the present study, we constructed a viscoelastic crustal structure model on the basis of their thermal structure model and carried out a simulation of the crustal deformation. If a viscoelastic crustal model is sufficiently realistic and the simulations well compare with the observed data, the crustal model can be refined. Consequently, it may become possible to model, for example, the postseismic crustal deformation after the 2011 Tohoku earthquake.

Copyright (c) The Society of Geomagnetism and Earth, Planetary and Space Sciences (SGEPSS); The Seismological Society of Japan; The Volcanological Society of Japan; The Geodetic Society of Japan; The Japanese Society for Planetary Sciences; TERRAPUB.

doi: $10.5047 /$ eps.2013.05.006
As for the stress regime of Japanese islands, extensive geological evidence has shown that since the late Neogene ( $2 \mathrm{Ma}$ ), Japanese islands have been subjected to compressional deformation in the east-west (EW) direction (Chinzei and Machida, 2001). Moreover, geodetic data for the past 100 years and GPS data for the past two decades show that EW compression has been going on in Japanese islands (Sagiya et al., 2000). The data on the stress orientation from focal mechanisms (Heidbach et al., 2010) indicate that Japanese islands are presently located in an EW compressional stress field.

On the basis of the background described above, we first modeled the 3D viscoelastic crustal structure (rheology structure) of Japanese islands and then conducted a 3D finite-element-method (FEM) simulation under boundary conditions of steady-state EW compression assuming time scales of a few decades to a few thousand years.

\section{Method}

\subsection{Viscoelastic crustal structure model}

The deformation of the crust and upper mantle can be described by the power-law relation

$$
\dot{\varepsilon}=A \sigma^{n} f_{\mathrm{H}_{2} \mathrm{O}}^{r} \exp [-(Q+p V) /(R T)],
$$

(e.g., Bürgmann and Dresen, 2008), where $\dot{\varepsilon}$ is the viscous strain rate; $\sigma$ is the flow strength (differential stress); $f_{\mathrm{H}_{2} \mathrm{O}}$ is the water fugacity; $p$ is the pressure; $R$ is the gas constant; $T$ is the absolute temperature. $A$ is the material constant; $Q$ the activation energy; $V$ the activation volume; and $n$ and $r$ the stress and fugacity exponents, respectively, all of which are determined by rock experiments for each mineral. We used the experimental results of quartz, anorthite, and olivine to model the viscosity for the upper crust, lower crust, and upper mantle, respectively (Table 1). We used Katsumata's (2010) results for the depth distribution 


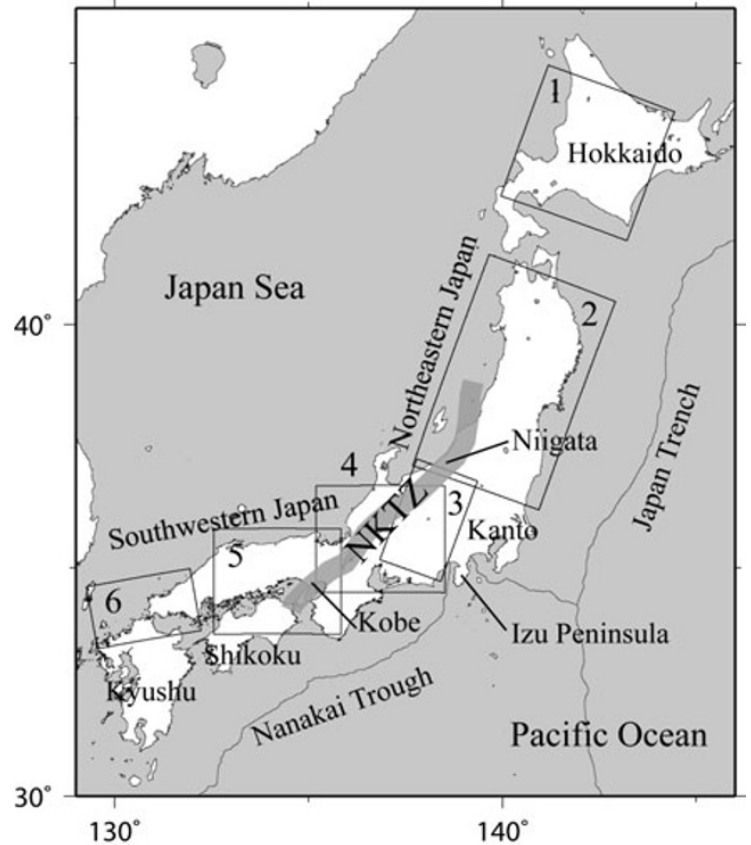

Fig. 1. Map of Japanese islands. The six rectangles indicate the target zones for the FEM calculations. The shaded region "NKTZ" indicates the deformation concentration zone inferred by Sagiya et al. (2000). The numbers assigned to the target zones correspond to the mesh numbers listed in Table 2.

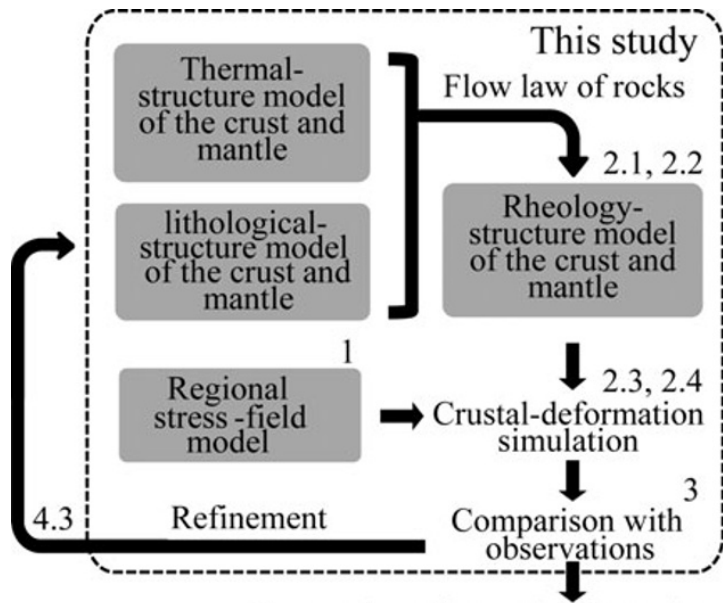

Forecasting of crustal deformation and earthquake generation

Fig. 2. Flow diagram for conducting forecasting simulations of the crustal deformation of Japanese islands and earthquake generations. Numerals correspond to the section numbers in this study.

of Conrad and Moho discontinuities. In addition, we used Matsubara et al. (2008)'s tomography data for the 3D distribution of $P$ - and $S$-wave velocities in the crust and upper mantle. The density distribution was converted from the distribution of the $P$-wave velocity on the basis of the empirical relation of Christensen and Mooney (1995). By combining Cho and Kuwahara's (2013) thermal structure model in the crust and upper mantle with this lithological model, we obtained a viscoelastic crustal structure model based on the constitutive law of power-law viscosity.
Table 1. Viscosity parameters ${ }^{\mathrm{a}}$.

\begin{tabular}{cccccc}
\hline Item & $\begin{array}{c}\log A \\
\left(\mathrm{MPa}^{-n} / \mathrm{s}\right)\end{array}$ & $n$ & $r$ & $\begin{array}{c}Q \\
(\mathrm{~kJ} / \mathrm{mol})\end{array}$ & $\begin{array}{c}V \\
\left(\mathrm{~cm}^{3} / \mathrm{mol}\right)\end{array}$ \\
\hline UC & -4.9 & 2.97 & 1.0 & 242. & 0 \\
LC & 0.2 & 3.0 & 1.0 & 345. & 38. \\
UM & 3.2 & 3.5 & 1.2 & 520. & 22. \\
\hline
\end{tabular}

Footnote: ${ }^{a}$ The parameters for the upper crust (UC), lower crust (LC), and upper mantle (UM) correspond to those for quartz, anorthite, and olivine from Rutter and Brodie (2004), Rybacki et al. (2006), and Hirth and Kohlstedt (2003), respectively.

\subsection{Simplification of the model}

To execute the FEM calculations while dealing with limited computer resources, we simplified the above viscoelastic crustal model. First, we converted the power-law viscosity into linear viscosity. More specifically, we calculated the flow strength $\sigma$ by assuming a uniform value of strain rate $\dot{\varepsilon}$ and assigning Cho and Kuwahara's (2013) temperature distribution to the above viscoelastic crustal model. Then, we calculated the effective viscosity coefficient $\eta_{e}$ by using the following relation:

$$
\sigma=\eta_{e} \dot{\varepsilon}
$$

We used $2 \times 10^{-15} \mathrm{~s}^{-1}$ (63 nanostrain/y) for $\dot{\varepsilon}$ as the representative strain rate for Japanese islands, which was deduced from the GPS data.

In the strength structure model thus obtained, there are parts where the strength is markedly low, such as directly below volcanic fronts, even though these parts are shallower than Conrad discontinuity. This feature was also indicated by Shimamoto (1992), who speculated the rheology structure of northeastern Japan on the basis of rock experiments. The viscoelastic crustal model in this study quantifies this idea. Meanwhile, the effective viscosity coefficient of the lower crust in our model takes values roughly on the order of $10^{20}-10^{21} \mathrm{~Pa}$ s.

Next, to further simplify the crustal model, we used only two values for the viscosity coefficient. We regarded the parts with an effective viscosity coefficient of $10^{22} \mathrm{~Pa} \mathrm{~s}$ (relaxation time $\sim 10,000$ years) or more as elastic zones (viscosity coefficient $\infty$ ) and the other parts as viscoelastic zones of a linear Maxwell material with a viscosity coefficient of $\eta=10^{21} \mathrm{~Pa}$ s. Finally, we obtained a simple crustal structure model, which has an elastic layer on top of a viscoelastic layer, with a 3D nonuniform thickness (Fig. 3). The elastic layer's thickness was $10-30 \mathrm{~km}$.

The distribution of the elastic constants is as described in Section 2.1 and the rigidity $\mu$ averages 34 and $67 \mathrm{GPa}$ at 10 and $60 \mathrm{~km}$ depth, respectively. The corresponding relaxation time $\tau_{\text {relax }}=\eta / \mu$ is 930 and 470 years, respectively.

\subsection{FEM mesh}

For the FEM calculations, we divided Japanese islands into six cuboids (target zones) because of computer capacity limitations, taking the $\mathrm{N} 90^{\circ} \mathrm{E}$ or $\mathrm{N} 110^{\circ} \mathrm{E}$ direction as the $x$ axis, the $\mathrm{N}^{\circ} \mathrm{E}$ or $\mathrm{N} 20^{\circ} \mathrm{E}$ direction as the $y$-axis, and the vertical downward direction as the $z$-axis (Fig. 1). The minimum side length of the target zones was $150 \times 250$ $\times 60 \mathrm{~km}$, and the maximum side length was $300 \times 500 \times$ $46 \mathrm{~km}$. We created an FEM mesh with respect to each target zone (Table 2). 
Table 2. Mesh parameters.

\begin{tabular}{c|c|ccc|cc}
\hline Mesh No. & Direction of the $x$-axis & Target zone & Physical size $\left(L_{x} \times L_{y} \times L_{z}[\mathrm{~km}]\right)$ & \multicolumn{2}{c}{ Number of elements } \\
& & $\mathrm{N} 20^{\circ} \mathrm{E}$ & $280 \times 290 \times 46$ & $3.14 \times 2.15 \times 2.00$ & $616 \times 638 \times 132$ & 251505 \\
Target zone & Whole zone \\
\hline 1 & $\mathrm{~N} 20^{\circ} \mathrm{E}$ & $300 \times 500 \times 46$ & $3.70 \times 3.70 \times 2.00$ & $660 \times 1100 \times 264$ & 251505 & 373402 \\
2 & $\mathrm{~N} 20^{\circ} \mathrm{E}$ & $150 \times 250 \times 60$ & $1.85 \times 1.85 \times 1.50$ & $330 \times 550 \times 132$ & 437400 & 601865 \\
3 & $\mathrm{~N} 0^{\circ} \mathrm{E}$ & $300 \times 250 \times 46$ & $3.70 \times 1.85 \times 2.00$ & $660 \times 550 \times 132$ & 251505 & 373402 \\
4 & $\mathrm{~N} 0^{\circ} \mathrm{E}$ & $300 \times 250 \times 46$ & $3.70 \times 1.85 \times 2.00$ & $660 \times 550 \times 132$ & 251505 & 373402 \\
5 & $\mathrm{~N} 10^{\circ} \mathrm{W}$ & $250 \times 150 \times 46$ & $3.09 \times 1.11 \times 2.00$ & $550 \times 330 \times 132$ & 251505 & 373465 \\
6 & & &
\end{tabular}

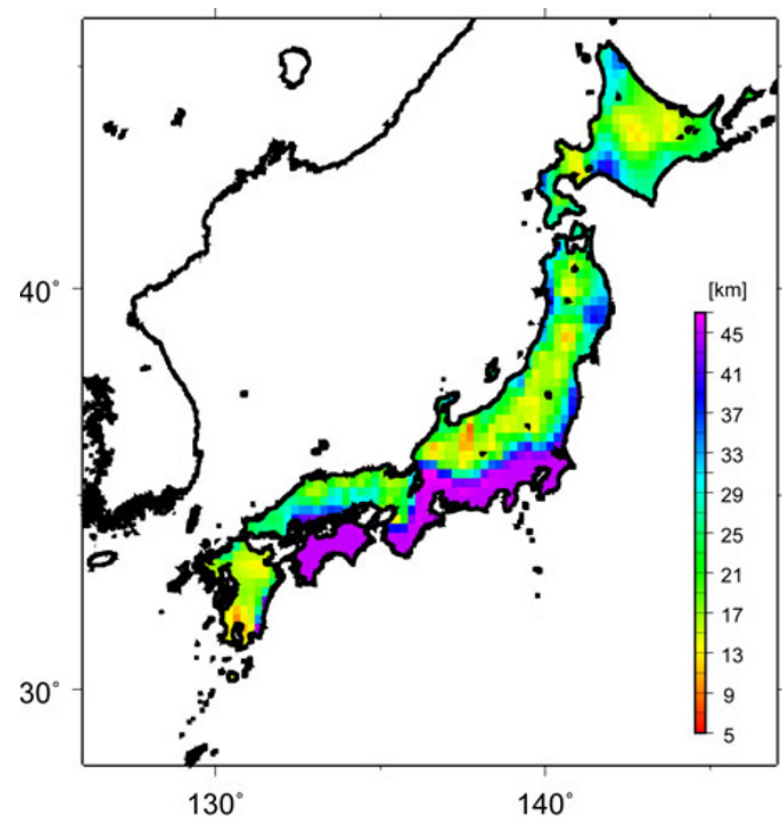

Fig. 3. Distribution of the elastic layer thickness.

Within each mesh, we divided the interior of the target zone into numerous hexahedral (cuboid) elements of uniform size. The element sizes were ranging from $1.85 \times$ $1.85 \times 1.5 \mathrm{~km}$ to $3.7 \times 3.7 \times 2.0 \mathrm{~km}$, according to the size of the target zone. The 3D distribution of the material properties in the target zone was given to each mesh. In order to reduce unwanted effects of the model boundaries, the area outside the target zone was enclosed in a large cuboid with side lengths 2.2 times those of the target zone (whole calculation zone). We used a technique whereby the elements inside the target zone become gradually coarser outside the zone (e.g., Lee et al., 2008) (Fig. 4). The total number of elements for each mesh was maintained at about 370,000 or 600,000 .

The 3D distribution of the material properties was given only inside the target zones. The material properties outside the target zones were extrapolated so that those on the side surfaces of the target zones continue without change. Thus, the whole calculation zone consists of an upper elastic layer and a viscoelastic layer beneath it.

\subsection{Boundary conditions and calculations}

The response of each target zone to uniform compression in the $x$-axis direction was evaluated using the FEM code PyLith (Williams et al., 2005; Williams, 2006; Aagaard et al., 2007, 2008a, b, 2013). For each mesh, we considered

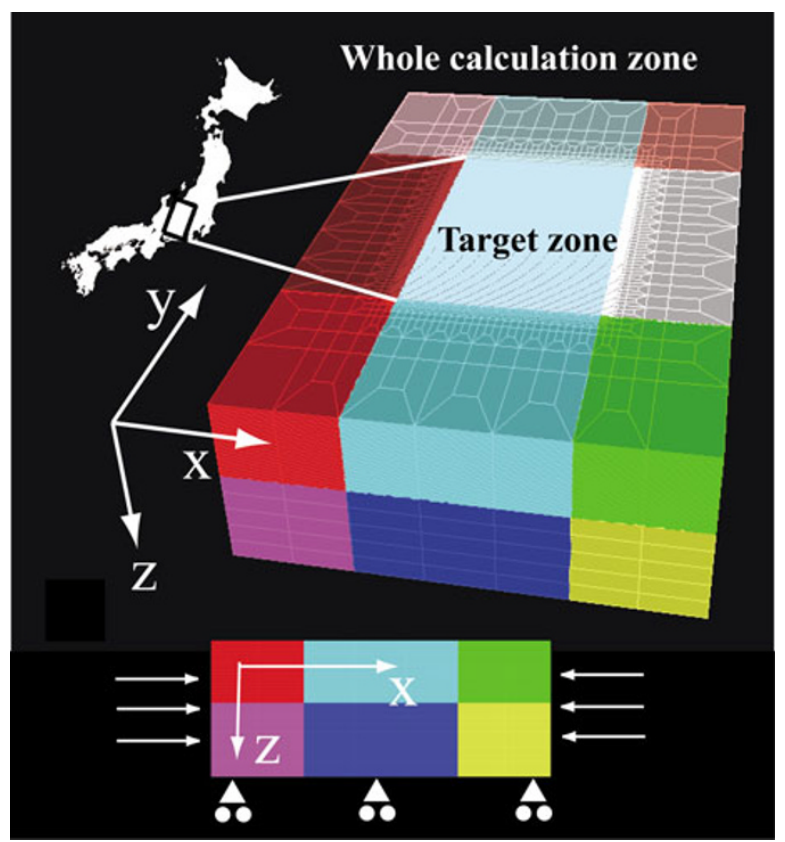

Fig. 4. Example view of an FEM mesh (Mesh No. 3). At the bottom, a cartoon depicting the boundary conditions for EW compression.

the ground surface to be a free surface and the displacement in the axial direction to be zero at the boundary surfaces of the whole calculation zone other than the $x$-axis direction (Fig. 4).

We adopted Matsu'ura and Sato's (1989) method to calculate the steady-state response as described in the following. Because our simplified crustal model is based on linear viscoelastic rheology, the displacement response at position $\mathbf{x}$ and time $t$ to steady-state compression by the boundary surfaces with a constant relative velocity $V$ can be represented by the hereditary integral

$$
\mathbf{u}(\mathbf{x}, t)=V \int_{0}^{t} \mathbf{U}(\mathbf{x}, t-\tau) d \tau,
$$

where the compression is assumed to start at time $t=$ 0 . $\mathbf{U}(\mathbf{x}, t)$ is the nondimensional displacement response at $(\mathbf{x}, t)$ relative to the unit compressional displacement of the boundary surfaces at $t=0$. By differentiating Eq. (3) with respect to $t$ and taking the limit $t \rightarrow \infty$, the steady-state velocity response is expressed as

$$
\dot{\mathbf{u}}(\mathbf{x})=V \mathbf{U}(\mathbf{x}, \infty),
$$

where the argument $t$ in $\mathbf{u}(\cdot)$ is abbreviated (Matsu'ura and Sato, 1989). 


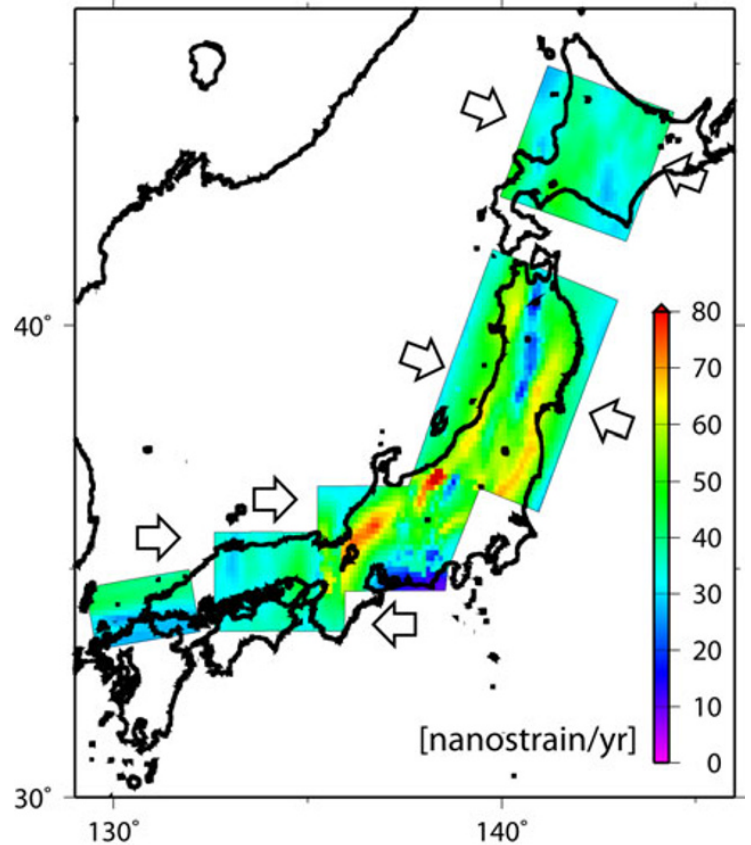

Fig. 5. Equivalent strain rate at the surface for the case where the EW compression rate is 50 nanostrain/y.

Practically, the limit $t \rightarrow \infty$ can be regarded as the time after complete relaxation. Giving the compressional unit displacement to the EW sides of the whole calculation zone by a step function and running the model for 100,000 years $\left(>100 \tau_{\text {relax }}\right)$, we regarded the calculated displacements factored by $V$ as the steady-state velocity response of the crustal model to the steady-state EW compression. Similarly, we regarded the calculation results of the strain (stress) as the steady-state strain (stress) rate.

\section{Results}

Figure 5 shows the distribution of the steady-state equivalent strain rate $\dot{T}_{e}$ at the ground surface, which is defined as $\dot{T}_{e}=\sqrt{3 \dot{\tau}_{i j} \dot{\tau}_{i j} / 2}$, where $\dot{\tau}_{i j}$ is the $i j$ component of the deviatoric strain rate tensor. Although target zones $2-5$ partially overlapped, the center points of the elements did not overlap. Thus, we drew Fig. 5 after smoothing the whole data at a uniform resolution of $0.11^{\circ}$ in the longitudinal and latitudinal directions. The figure shows that the strain accumulates at a high rate in the zone from Niigata to Kobe. The strain rate is also high on the coast of Niigata in the Sea of Japan and further north, and on the Pacific Ocean coast. This distribution pattern at locations other than the north of northeastern Japan along the Pacific Ocean coast corresponds well with the deformation concentration zone inferred from the GPS data, known as the Niigata-Kobe tectonic zone (NKTZ) (figure 5 in Sagiya et al., 2000).

Quantitatively, the observed average strain rate in NKTZ according to GPS is 50-75 nanostrain/y, and near central Japan, the peak value is 150 nanostrain/y. In the regions outside NKTZ where the strain rate is low, the value is 2550 nanostrain/y and there are areas where it is less (Sagiya et al., 2000). On the other hand, our simulation results are scaled to the mean strain rate of EW compression given a priori by the boundary condition. If the applied mean strain

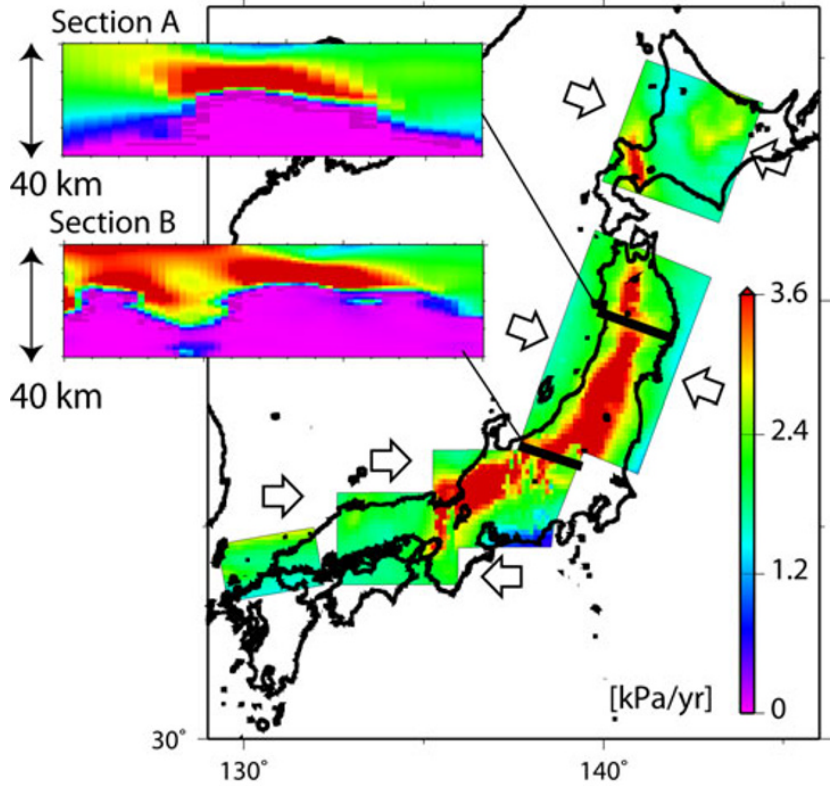

Fig. 6. Equivalent stress rate for an EW compression rate of 50 nanostrain/y. In the horizontal cross sections, the depth is $10 \mathrm{~km}$. In the vertical cross sections, the pink parts represent the viscoelastic zone with zero stress rate, and the green and red parts indicate the elastic layer.

rate is 50 nanostrain/y, the strain rates in the NTKZ are 50 80 nanostrain/y, which matches well with the GPS data; There is also a peak exceeding 80 nanostrain/y at almost the same point as the peak in the GPS data; In the part with a low strain rate outside NKTZ, the strain rate is $30-50$ nanostrain/y.

In the GPS data of Sagiya et al. (2000), there are zones with high strain rate outside NKTZ on the forearc side, particularly in Shikoku, and the southern coastal areas of Kanto and Hokkaido. However, the strain rate in the corresponding zones in Fig. 5 is not that high. This is likely because, while the strain on the forearc side in the GPS data is considered to largely involve elastic strain that cyclically accumulates during interseismic periods of about 100 years because of the subducting oceanic plates, these effects are not considered in steady-state simulation.

\section{Concluding Discussion and Future Problems 4.1 Origin of NKTZ}

Our simulation results indicate that the origin of NKTZ lies in the crust's viscosity structure. Many previous studies have also looked at the viscosity structure as the origin of NKTZ (e.g., Hyodo and Hirahara, 2003; Iio et al., 2004; Yamasaki and Seno, 2005; Nakajima and Hasegawa, 2007), and our results agree with past research. Following are the original features of this study: A comparison of Figs. 3 and 5 indicates that NKTZ is not a region with a uniform thin elastic layer, as modeled by Hyodo and Hirahara (2003), but rather a region of strong 3D nonuniformity in the elastic layer's thickness. Where the elastic layer is thin, the stress and strain rates are high at the deep parts near the boundary between the elastic and viscoelastic layers. The parts that have high stress and strain rates do not continue directly above the boundary, but at an upward slant (Fig. 6, Section 
A). As a result, there is apparent discrepancy between the NKTZ observed at the surface and the distribution of the high-stress zone at a depth of $10 \mathrm{~km}$. This discrepancy is clearer in northeastern Japan. In central Japan, interestingly, there are regions where the slanted upward extensions of the high-stress and -strain rate zones overlap and are enhanced at the surface (Fig. 6, Section B).

To the best of our knowledge, this is the first study to indicate the possibility of a shift in the position with high accumulation rate of deep stress and strain relative to the surface (NKTZ). This has not been previously pointed out probably because there has not been an attempt to construct a realistic $3 \mathrm{D}$ model of the viscoelastic crustal structure because of the limited information available on the deep crust. The present results show the importance of establishing a method for constructing a realistic model for the viscoelastic crustal structure, which is also three-dimensionally nonuniform. In this paper, we make notice of this important issue, even though this is a preliminary crustal model.

Incidentally, when drawing Figs. 5 and 6, we assumed time scales of a few decades to a few thousand years. When one assumes a time scale much longer than the recurrence times of intraplate earthquakes (e.g., longer than $10^{5}$ years), plasticity should be incorporated to the crustal model, as done by Shibazaki et al. (2007, 2008). Consequently, the stress distribution within the elastic layer will be significantly different from that in Fig. 6 if plasticity is taken into account: The distribution pattern in Fig. 6 is expected to resemble that of the plastic strain rate.

\subsection{On the simplification of the crustal model}

In this study, we used a simple crustal model with linear viscous rheology mainly because of the applicability of Matsu'ura and Sato (1989)'s method for simulating the generation of earthquakes as well crustal deformation. The Matsu'ura and Sato (1989)'s method has the following advantages. (i) In their method, the crustal deformation or stress accumulation is divided into a steady-state part and a perturbation part that correspond to steady-state plate motions and earthquake events, respectively. This separation is useful for assessing the system behavior. In the present study, we used the steady-state part only. (ii) The steadystate part is represented by a complete relaxation solution (Section 2.4); therefore, the response in the elastic part does not depend on the viscosity coefficient. This feature can largely solve the problem of ambiguity in the viscosity distribution deep in the crust. (iii) In this respect, a single viscosity coefficient value is adequate for the crustal model, as done in this study. As a result, we can easily adjust the time increments and the end time of the calculations to obtain a steady-state solution, and thus can reduce the computation time.

Of course, we have to separately evaluate the effects of using linear instead of nonlinear rheology in the calculations (e.g., stress/strain localization). However, on the other hand, some simplification of the crustal model is necessary to decrease the calculation time and carry out the items listed in the following section. When focusing on forecasting and considering the ambiguities in the distribution of the various parameters deep in the crust, we believe that the simplification of the crustal model in this study is presently an adequate solution.

\subsection{Future problems}

To conduct more realistic simulations of crustal deformation and forecasting, the viscoelastic crustal structure model presented in this paper needs to be next examined according to items (i) and (ii) below. The examination of items (iii) and (iv) below is also necessary to further refine the model by comparing the simulations with the GPS data.

(i) It is necessary to perform considerable FEM calculations to examine the effects of variations in the parameters of the constitutive law and of mineral distributions of the crust on the simulation results. The same holds for the parameters related to the simplification of the viscoelastic crustal structure model, e.g., a critical value of the viscosity coefficient to divide the crustal model into an elastic part and a viscoelastic part.

(ii) There are regions in Japanese islands that should be modeled with a boundary condition other than EW compression, e.g., the collision zone around the Izu Peninsula or the rift zone in central Kyushu. These areas are excluded from the target zone in this study.

(iii) The model needs to incorporate a factor to take into account the elastic strain that cyclically accumulates during interseismic periods of the subduction zone earthquakes occurring along the Japan Trench and the Nankai Trough.

(iv) The model also needs to incorporate several factors to take into account the afterslip on a fault plane and the transient viscous relaxation in the crust after large inland earthquakes, as well as the steady slip in the deep part. To achieve this, we need to model the deep extension of the active faults that lie within the inland areas of Japanese islands.

Acknowledgments. Data on the Conrad and Moho discontinuity depths were provided by Dr. Akio Katsumata. Constructive comments by anonymous reviewers significantly improved the manuscript.

\section{References}

Aagaard, B., C. Williams, and M. Knepley, PyLith: A finite-element code for modeling quasi-static and dynamic crustal deformation, Eos Trans. $A G U, \mathbf{8 8}(52)$, Fall Meet. Suppl., Abstract T21B-0592, 2007.

Aagaard, B., C. Williams, and M. Knepley, PyLith: A finite-element code for modeling quasi-static and dynamic crustal deformation, Eos Trans. $A G U, \mathbf{8 9}(53)$, Fall Meet. Suppl., Abstract T41A-1925, $2008 \mathrm{a}$.

Aagaard, B., S. Kientz, M. Knepley, L. Strand, and C. Williams, PyLith user manual version 1.3, Pasadena, CA: Computational Infrastructure of Geodynamics, http://geodynamics.org, 2008b.

Aagaard, B. T., M. G. Knepley, and C. A. Williams, A domain decomposition approach to implementing fault slip in finite-element models of quasi-static and dynamic crustal deformation, J. Geophys. Res., 118, 3059-3079, doi:10.1002/jgrb.50217, 2013.

Bürgmann, R. and G. Dresen, Rheology of the lower crust and upper mantle: Evidence from rock mechanics, geodesy, and field observations, Ann. Rev. Earth Planet. Sci., 36, 531-567, 2008.

Chinzei, K. and H. Machida, Geomorphic development in Japanese islands, in Regional Geomorphology of the Japanese Islands, vol. 1, Introduction to Japanese geomorphology, edited by N. Yonekura et al., pp. 297-322, University of Tokyo Press, 2001 (in Japanese).

Cho, I. and Y. Kuwahara, Constraints on the three-dimensional thermal structure of the lower crust in the Japanese Islands, Earth Planets Space, 65, 855-861, 2013.

Christensen, N. I. and W. D. Mooney, Seismic velocity structure and composition of the continental crust: A global view, J. Geophys. Res., 100, 
9761-9788, 1995.

Heidbach, O., M. Tingay, A. Barth, J. Reinecker, D. Kurfeß, and B. Müller, Global crustal stress pattern based on the World Stress Map database release 2008, Tectonophysics, 482, 3-15, doi:10.1016/j.tecto.2009.07.023, 2010

Hirth, G. and D. L. Kohlstedt, Rheology of the upper mantle and the mantle wedge: a view from the experimentalists, in Inside the Subduction Factory, edited by J. Eiler, pp. 83-105, Geophys. Monogr, 138, Am. Geophys. Soc., 2003.

Hyodo, M. and K. Hirahara, A viscoelastic model of interseismic strain concentration in Niigata-Kobe tectonic zone of central Japan, Earth Planets Space, 55, 667-675, 2003.

Iio, Y., T. Sagiya, and Y. Kobayashi, Origin of the concentrated deformation zone in the Japanese islands and stress accumulation process of intraplate earthquakes, Earth Planets Space, 56, 831-842, 2004.

Katsumata, A., Depth of the Moho discontinuity beneath the Japanese islands estimated by traveltime analysis, J. Geophys. Res., 115, B04303, doi:10.1029/2008JB005864, 2010.

Lee, S.-J., H.-W. Chen, Q. Liu, D. Komatitsch, B.-S. Huang, and J. Tromp, Three-dimensional simulations of seismic-wave propagation in the Taipei basin with realistic topography based upon the spectral-element method, Bull. Seismol. Soc. Am., 98, 253-264, doi: 10.1785/0120070033, 2008.

Matsubara, M., K. Obara, and K. Kasahara, Three-dimensional P- and Svelocity structures beneath the Japan islands obtained by high-density seismic stations by seismic tomography, Tectonophysics, 454, 86-103, doi:10.1016/j.tecto.2008.04.016, 2008.

Matsu'ura, M. and T. Sato, A dislocation model for the earthquake cycle at convergent plate boundaries, Geophys. J., 96, 23-32, 1989.

Nakajima, J. and A. Hasegawa, Deep crustal structure along the NiigataKobe tectonic zone, Japan: Its origin and segmentation, Earth Planets Space, 59, e5-e8, 2007.

Nakajima, J. and A. Hasegawa, Seismic evidence for thermally-controlled dehydration reaction in subducting oceanic crust, Geophys. Res. Lett., 36, L03303, doi:10.1029/2008GL036865, 2009.
Rutter, E. H. and K. H. Brodie, Experimental intracrystalline plastic flow in hot-pressed synthetic quartzite prepared from Brazilian quartz crystals, J. Struct. Geol., 26, 259-270, doi:10.1016/j.jsg.2004.04.006, 2004.

Rybacki, E., M. Gottschalk, R.Wirth, and G. Dresen, Influence of water fugacity and activation volume on the flow properties of fine-grained anorthite aggregates, J. Geophys. Res., 111, B03203, doi:10.1029/2005JB003663, 2006.

Sagiya, T., S. Miyazaki, and T. Tada, Continuous GPS array and presentday crustal deformation of Japan, Pure Appl. Geophys., 157, 2303 2322, 2000.

Shibazaki, B., K. Garatani, and H. Okuda, Finite element analysis of crustal deformation in the Ou backbone range, northeastern Japan, with non-linear visco-elasticity and plasticity: effects of non-uniform thermal structure, Earth Planets Space, 59, 499-512, 2007.

Shibazaki, B., K. Garatani, T. Iwasaki, A. Tanaka, and Y. Iio, Faulting processes controlled by the nonuniform thermal structure of the crust and uppermost mantle beneath the northeastern Japanese island arc, $J$. Geophys. Res., 113, B08415, doi:10.1029/2007JB005361, 2008.

Shimamoto, T., Rheology of rocks and plate tectonics, in Comprehensive Rock Engineering, vol. 1: Fundamentals, edited by E. T. Brown, pp. 93108, Pergamon Press, Oxford, 1992.

Williams, C. A., Development of a package for modeling stress in the lithosphere, Eos Trans. AGU, 87(36), Jt. Assem. Suppl., Abstract T24A01, 2006.

Williams, C. A., B. Aagaard, and M. G. Knepley, Development of software for studying earthquakes across multiple spatial and temporal scales by coupling quasi-static and dynamic simulations, Eos Trans. AGU, 86(52), Fall Meet. Suppl., Abstract S53A-1072, 2005.

Yamasaki, T. and T. Seno, High strain rate zone in central Honshu resulting from the viscosity heterogeneities in the crust and mantle, Earth Planet. Sci. Lett., 232, 13-27, doi:10.1016/j.eps1.2005.01.015, 2005.

I. Cho (e-mail: ikuo-chou@aist.go.jp) and Y. Kuwahara 